\title{
CFD-aided benchmark assessment of coal devolatilization one-step models in oxy-coal combustion conditions
}

\author{
Salvatore Iavarone ${ }^{\mathrm{a}, *}$, Chiara Galletti ${ }^{\mathrm{b}}$, Francesco Contino $^{\mathrm{c}}$, Leonardo Tognotti ${ }^{\mathrm{b}}$, Philip J. Smith ${ }^{\mathrm{d}}$, Alessandro \\ Parente $^{\mathrm{a}}$ \\ ${ }^{a}$ Université Libre de Bruxelles, Ecole Polytechnique de Bruxelles, Aero-Thermo-Mechanics Laboratory, Bruxelles, Belgium \\ ${ }^{b}$ University of Pisa, Department of Civil and Industrial Engineering, Pisa, Italy \\ ${ }^{c}$ Vrije Universiteit Brussel, Department of Mechanical Engineering, Brussels, Belgium \\ ${ }^{d}$ University of Utah, Department of Chemical Engineering, Salt Lake City, UT, USA
}

\begin{abstract}
Coal devolatilization, as first step in thermochemical processes involving solid fuels, has been targeted in plenty of CFD investigations: despite the variety of models that were developed to define the rate of the process and the amount of volatile matter released, not all of them are suitable for CFD simulations of large-scale coal combustors. Empirical models are therefore necessary because they ensure both simplicity and feasibility, but not full reliability for coal types and operating conditions. CFD modeling results for coal conversion during devolatilization in an entrained flow reactor and oxy-conditions are presented and compared to experimental data. A benchmark assessment of one-step models on the accuracy of the volatile yield prediction is then performed. It is shown that the heating rate strongly influences the devolatilization process and its modeling, not only in terms of rate but also in terms of yield, which differs significantly from the proximate analysis value: a thermodynamic model that predicts the coal volatile yield changes with temperature and heating rate, in addiction to a kinetic model, is necessary.

Keywords: Coal devolatilization; Oxy-coal combustion; Entrained flow reactor; CFD modeling; One-step kinetic models.
\end{abstract}

\section{Introduction}

The current period of environmental awareness will end up to the closure of the era of fossil fuels, such as coal, as main sources for power generation. Avoiding the average global surface temperature increase of $2 \mathrm{~K}$ over the pre-industrial average would require the world to move rapidly toward $100 \%$ clean energy, producing zero net greenhouse gas emissions between about 2050 and 2080. In the meantime, the use of coal cannot be totally avoided. The large availability, the broad worldwide distribution and the low cost make coal a leading energy resource for the power generation in the world, despite the global market share of renewable energy sources has significantly increased. Moreover, coal will remain a major source for the next few decades [1], although its use is affected by environmental concerns, regarding the emission of carbon, nitrogen and sulfur oxides and the formation of aerosol particles. The so-called clean coal technologies, able to reduce the emission of these pollutants, can achieve a right compromise between environmental and economical needs in the power generation industry. Among them, the oxy-combustion is one of the most interesting: it allows higher volatile release and char burnout, flame ignition

${ }^{*}$ Corresponding author. Phone +32265026 73. Address: Avenue F. D. Roosevelt 50, 1050 Bruxelles, Belgium.

Email address: Salvatore.Iavarone@ulb.ac.be (Salvatore Iavarone)

(C) 2016. This manuscript version is made available under the Elsevier user license

http://www.elsevier.com/open-access/userlicense/1.0/ 
delays, improvement of $\mathrm{CO}_{2}$ capture and sequestration, lower emissions in terms of nitrogen oxides, sulfur oxides and particulate matter and represents a competitive technological option for retrofitting existing coal-fired power plants 2]. Simulation tools like Computational Fluid Dynamics (CFD) are extremely useful to develop industrial-scale oxy-combustor, avoiding scaling-up procedures that can be challenging due to the strong interactions between many phenomena such as turbulence, reaction and heat release. A realistic reproduction of coal combustion process in CFD simulations relies on the implementation of detailed kinetic mechanisms describing coal devolatilization, char oxidation, gas-phase reactions and pollutant formation [3], generally involving hundreds of species and thousands of reactions. For real combustors, characterized by large computational grids, this implementation can be challenging to achieve, due to significant computational efforts required, especially in the Large Eddy Simulation (LES) framework. Simplified mechanisms able to ensure the main features of the detailed ones at an affordable cost are needed. For coal devolatilization, a variety of models were developed to define the rate of the process and the amount of volatile matter released. These models were validated on experimental data usually taken from thermogravimetric analysis (TGA) and drop tube reactor (DTR) experiments [4 6], although the entrained flow reactors (EFRs) are recently emerging as the most viable way for validation of solid fuel behavior at temperatures and heating rates typical of industrial combustion devices. Indeed, EFRs could provide the most valuable validation dataset for predicting the ignition behavior of coal and the heating rate influence on coal devolatilization in industrial boilers [7 $[9]$.

The present work proposes a benchmark of one-step devolatilization models with respect to the accuracy of the volatile yield prediction: one-step models have been implemented and validated against experimental data coming from tests performed in an entrained flow reactor and in oxy-conditions, in order to shed light on their drawbacks, benefits and improvability. One-step models have been chosen because of their simplicity: they can be easily included in CFD codes and are very interesting in the perspective of LES of pulverized coal combustion burners. Calibration of kinetic parameters is required to allow the models to be predictive and reliable for different heating rates, hold temperatures and coal types. A comparison of several calibration approaches have been performed to determine if one-step models can be also adaptive and able to bridge scales without losing accuracy, and to select the calibration method to employ for wider ranges of coal rank and operating conditions.

\section{Devolatilization modeling}

Complex phenomenological models [10 12], and several empirical models [13 15] have been proposed for coal devolatilization. The phenomenological approaches are potentially applicable to wide ranges of coal composition and operating conditions, being generally very accurate, but computationally expensive. Instead, empirical approaches are applied to specific coals and operating conditions. Among them, the Single First Order Reaction (SFOR) model calculates the overall pyrolysis rate by means of the following expression:

$$
\frac{d X}{d t}=A \exp \left(-\frac{E}{R T_{p}}\right)\left(X_{f}-X\right)
$$

In Equation 1, $X$ is the volatile yield, or particle conversion, $t$ is the time, $R$ the ideal gas constant and $T_{p}$ the absolute temperature of the particle. It requires two kinetic parameters, i.e. the pre-exponential factor $A$ and the activation energy $E$ of an "artificial" first-order kinetic rate expression, and the final volatile matter yield $X_{f}$. The temperature dependency of the devolatilization rate is described by the Arrhenius equation; however, it cannot 
accurately follow the complex competing reactions taking place during pyrolysis, which are activated at different temperature ranges [3]. Furthermore, the final volatile yield $X_{f}$ remains constant at different heating rates and final temperatures, unlike the behavior from what observed in experiments [16]. A simple modification of the SFOR model by assuming that the $X_{f}$ term is a function of temperature was proposed by Biagini and Tognotti [17. In their work, $X_{f}$ changes according to particle temperature with the following expression:

$$
X_{f}=1-\exp \left(-D I \frac{T_{p}}{T_{s t}}\right)
$$

In Equation 2, $D I$ is the so-called Devolatilization Index, a dimensionless parameter specific for each coal, $T_{p}$ is the particle temperature and $T_{s t}$ is the proximate analysis "standard temperature", equal to $1223 \mathrm{~K}$. Linear correlations between coal properties and devolatilization kinetic parameters in a range of coal compositions and operating conditions have been proposed by Biagini and Tognotti, having the following general form:

$$
P=m V+q,
$$

where $P$ is a model parameter $(A, E$ or $D I), V$ is a fuel parameter and $m$ and $q$ are the determined correlation parameters. The parameters were derived through an optimization procedure applied to a specific devolatilization data set extracted from the Solid Fuel DataBase (SFDB) of International Flame Research Foundation (IFRF) [18]. Biagini and Tognotti verified that the best linear regressions (i.e., with the highest value of squared Pearson coefficient $R^{2}$ ) are for $D I$ with $V M$ (Volatile Matter from the proximate analysis), $E$ with $O / C$ (Oxygen-to-Carbon mass ratio), and $\ln (A)$ with $E$, even though $E$ is not a fuel parameter per se.

The values of $m$ and $q$ and the specification of model and fuel parameters are reported in Table 1 . The performances of the Biagini and Tognotti (B-T) model have been assessed in our research.

\begin{tabular}{cccc}
\hline $\mathrm{P}$ & $\mathrm{V}$ & $\mathrm{m}$ & $\mathrm{q}$ \\
\hline $\mathrm{E}(\mathrm{kJ} / \mathrm{mol})$ & $\mathrm{O} / \mathrm{C}$ & 30.4 & 24.6 \\
$\ln (\mathrm{A})$ with A in $\left(\mathrm{s}^{-1}\right)$ & $\mathrm{E}(\mathrm{kJ} / \mathrm{mol})$ & 0.105 & 3.42 \\
$\mathrm{DI}$ & $\mathrm{VM}(\%$ wt dry $)$ & 0.0219 & -0.208 \\
\hline
\end{tabular}

Table 1: Parameters for the generalized correlations in Equation 3.

In several previous CFD modeling works upon coal combustion, the pyrolysis mechanism has been described using one-step kinetic models [19 22]. Given the high sensitivity of kinetic constants to heating rates and hold temperatures of particles, an iterative procedure between the devolatilization model calibration and the CFD computations may produce better results [9]. However, most CFD simulations consider these models without any calibration, just using reference parameters taken from technical literature, e.g. see [23 26]. The adoption of SFOR parameters taken from literature can give inaccurate predictions of the volatile yield, because they are validated for temperatures and heating rates lower than those typical of industrial plants. In absence of industrial-like experiments, phenomenological network models can be used for the calibration of one-step models at heating rates and temperatures higher than those in drop tube or thermal gravimetric analysis (TGA) experiments [27 29]. To avoid the use of complex structural models, and so to limit the computational efforts, a methodology for calibration of simple models is proposed, 
based on experimental data and CFD simulations of an EFR operating at conditions close to the ones encountered in industrial systems. The methodology focuses on the main drawback of one-step models: the dependency of ultimate volatile yield and kinetic parameters on the actual thermal conditions. The SFOR models with calibrated parameters have been compared to the Chemical Percolation Devolatilization (CPD) model [11], representative of phenomenological models. CPD describes the devolatilization behavior of rapidly heated coal based on the chemical structure of the parent coal, using features of the chemical structure that are directly measured by 13-C nuclear magnetic resonance (NMR) spectroscopy. The model includes a bridge-breaking reaction scheme, lattice statistics, percolation theory, and chemical phase-equilibrium calculations; it assumes a uniform temperature throughout the particle and extremely small Biot number, allowing the model outputs to be scaled by the mass of the desired particle size. Rate coefficients are assumed to be coal-independent and sequential distributed activation energy is considered. Utilizing CPD for this study was meant as a benchmark to test the reliability of the following calibrated SFOR models, besides validating CPD itself.

\section{Methodology}

\subsection{Experimental data}

The source of the experimental data considered in this work is the Isothermal Plug Flow Reactor (IPFR), an entrained flow reactor of the International Flame Research Foundation (IFRF). A brief description of the geometrical, operating and diagnostic parameters of the IPFR in the site of Livorno (Italy) can be found in 30 33. IPFR allows testing solid fuels under conditions similar to industrial applications with high temperatures (1000-1600 K) and heating rates $\left(10^{4}-10^{5} \mathrm{~K} / \mathrm{s}\right)$. The residence time is up to 2 seconds. The reactor inner tube is $4.5 \mathrm{~m}$ long with a diameter of $0.15 \mathrm{~m}$. At the walls, nine modules equipped with electric resistances (globally $54 \mathrm{~kW}$ ) keep the temperature at a set point value. Each module has several ports which are available for coal injection or for the insertion of measuring instruments. Pulverized fuel particles are transported by a carrier gas (nitrogen/air $/ \mathrm{CO}_{2}$ ) and injected from a side through a radial probe into a flue gas stream, coming from a pre-heating combustion section located at the top section of the reactor, and move along the reactor (see Figure 1).

The solid residue and gaseous products are quenched and sampled in the collection probe for online and offline analyses: proximate, ultimate, particle size distribution and ash composition. The ash content of the solid residue is then compared to that of the parent coal for calculating the conversion with the ash tracer method, according to the following expression:

$$
X=1-\frac{a s h_{0}}{a s h} \times \frac{1-a s h}{1-a s h_{0}},
$$

where $a s h_{0}$ and ash are respectively the initial and current mass fraction of ash, calculated on dry basis [30]. Conversions, kinetics and other specific test parameters can be obtained for several fuels under proven procedures that give uniform and reliable data. Each experimental result is defined by a value of the nominal particle residence time, the nominal reactor temperature, the volatile matter released and the devolatilization conversion. The experimental data used in our investigation are the results of three devolatilization tests at 1173, 1373 and $1573 \mathrm{~K}$, performed on the bituminous coal Sebuku, whose proximate and ultimate analysis are reported in Table 2, The oxygen mass fraction in the flue gases is kept as close to zero as possible. Thus, the coflow composition, in terms 


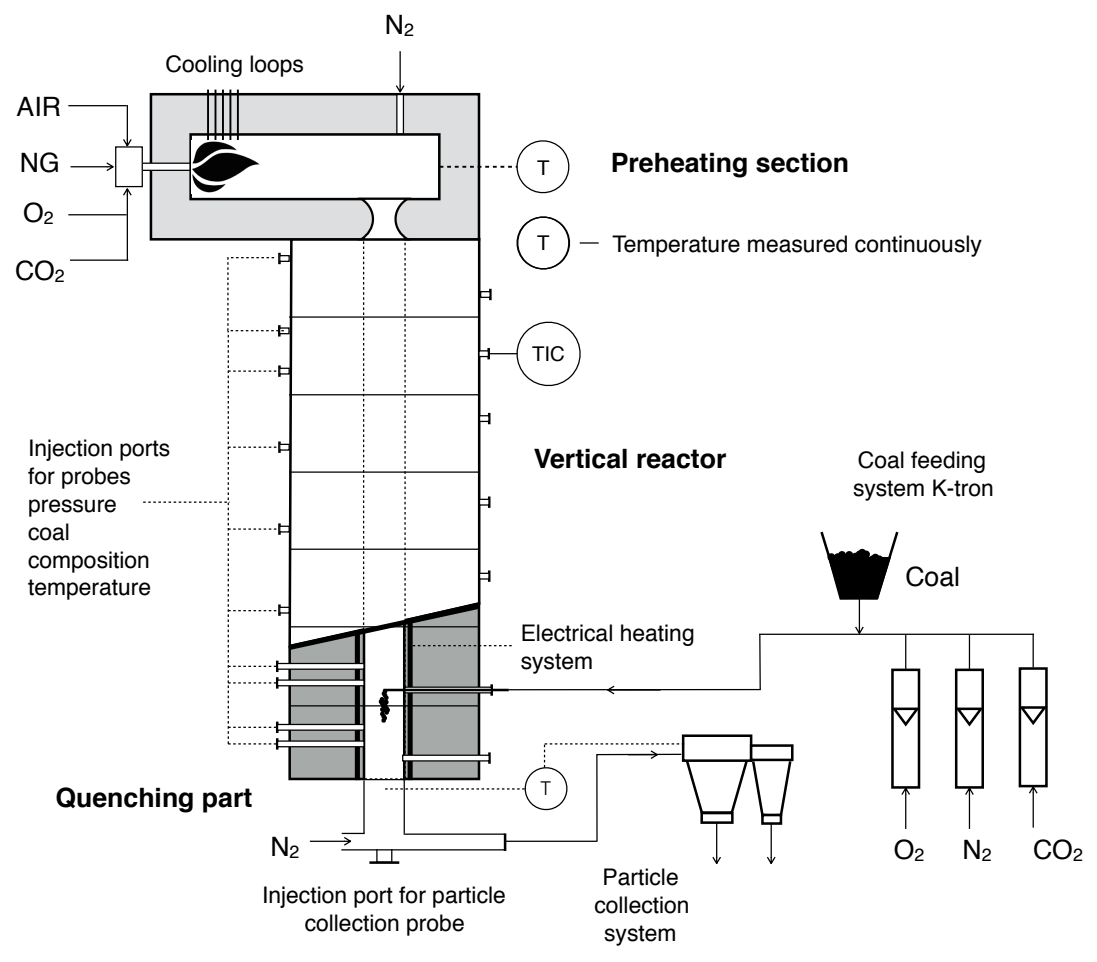

Figure 1: Scheme of Isothermal Plug Flow Reactor [17.

of mass fractions, is less than $2 \% \mathrm{O}_{2}, 10-15 \% \mathrm{CO}_{2}, 8-13 \% \mathrm{H}_{2} \mathrm{O}$ and $\mathrm{N}_{2}$ as remainder. The flue gases from the preheating section enters the reactor with a flow rate of $14.6-17.6 \mathrm{Nm}^{3} / \mathrm{h}$. Carbon dioxide is used as carrier gas for the injection of solid particles. The carrier stream approaches the reactor at $293 \mathrm{~K}$ with a flow rate of 0.5-0.6 $\mathrm{Nm}^{3} / \mathrm{h}$.

The devolatilization tests examined in this paper were performed in a conventional combustion environment, but using carbon dioxide as carrier gas. This because the particle residence times were so low that they did not have enough time to mix with the surrounding gases; rather, they were heated up and devolatilized in an atmosphere rich in carbon dioxide. The residence times were also lower, by at least one order of magnitude, than the characteristic times of coal gasification reaction with $\mathrm{CO}_{2}$, estimated using the reaction rate coefficients reported in [3, 34]. Thus, the mass release due to the gasification reaction can be neglected, or most reasonably embedded within the experimental uncertainty. Moreover, as indicated in the IFRF experimental report, similar results on ultimate volatile yield are obtained in different gas environments, with $\mathrm{CO}_{2}$ and $\mathrm{H}_{2} \mathrm{O}$ mass fraction ranging from 10 to $78 \%$ and 18 to $22 \%$, respectively, and $\mathrm{O}_{2}$ mass fraction set to $1 \%$. Indeed, different devolatilization tests were performed at $1573 \mathrm{~K}$, namely devolatilization in a conventional atmosphere using $\mathrm{CO}_{2}$ as carrier gas, devolatilization in a totally oxy-fuel atmosphere and devolatilization in a conventional atmosphere using nitrogen as carrier gas. These results also suggest that the influence of the gasification is negligible.

No measurements of the solid phase temperature were performed, assuming the nominal reactor temperature was uniformly and quickly reached. The carrier gas flow rate is almost thirty times lower than the coflow 
rate, so that a small influence on the particle heating rate and temperature is expected. The particle residence time is calculated by taking into account the length of the particles path within the vertical reactor, i.e. the distance between injection and sampling height, and the mean velocity of the flue gases [32]. A 4\% relative error was estimated by the experimenters to affect the conversion values almost constantly, regardless of the temperature but related to the composition of ash, the inhomogeneity of the collected sample and the accuracy of the proximate analyzer [32]. However, the different replicates available from the experimental campaigns show that the maximum experimental error is larger than the "estimated" $4 \%$ and equal to 19\% (this error is then considered affecting all the data). Concerning the particles residence time in the IPFR, the following uncertainties were quantified: an average error of about $2 \%$, constant with temperature and residence time, due to the measurement error of flue gas mass flow, and an additional 1-2 ms error, function of the temperature, whose weight can vary between $0.1 \%$ (for a 1000 $\mathrm{ms}$ high-temperature test) and $8 \%$ (for a $25 \mathrm{~ms}$ low-temperature one), due the sampling probe positioning accuracy of about 3-4 $\mathrm{mm}[32$.

\begin{tabular}{ccccccccccc}
\hline \multirow{2}{*}{ Coal type } & Particle size (tm) & \multicolumn{3}{c}{ Proximate Analysis (\%dry) } & \multicolumn{5}{c}{ Ultimate Analysis (\%dry) } \\
\cline { 2 - 10 } & & VM & FC & Ash & C & H & N & S & O \\
\hline Sebuku & $65-90$ & 40.30 & 47.95 & 11.75 & 62.75 & 4.66 & 1.27 & 0.48 & 19.10 \\
\hline
\end{tabular}

Table 2: Sebuku coal characteristic properties.

\subsection{Derivation of SFOR kinetic parameters}

Several procedures are proposed to bridge the gap between detailed pyrolysis models and empirical models based on single-step kinetic expressions, which are usually used in CFD. The overall methodology for the calibration of simple models avoids the use of phenomenological models and exploits CFD and experimental data.

The first approach considers the particle temperature constant and equal to the nominal IPFR temperature. A multivariable optimization on the pre-exponential factor, the activation energy and the ultimate volatile yield is extended to all the conversion data available from the IPFR tests and performed to minimize the error, namely the root-mean-squared error (RMSE), between experimental and modeled conversion over residence time. The latter is derived through CFD simulations of the IPFR. The method is conventional for derivation of kinetic parameters and it is iterative: the particle residence time is firstly calculated from simulations with injection of inert particles and subsequently, once first kinetic parameters are evaluated, from simulations with reactive particles. These steps are repeated until the convergence of the CFD calculation result is achieved.

In the second approach, both the particle temperature and the residence time are derived from the CFD modeling of the IPFR, at 1173, 1373 and $1573 \mathrm{~K}$. The particles undergo a transient heating phase before the achievement of the nominal temperature. An analytical integration of the SFOR equation over time is performed, taking into account a plausible approximation of particle thermal history, e.g. a linear relation between temperature and time that replaces the constant temperature, previously supposed in the first approach, in the equation. For the sake of clarity, the thermal history of the particles is defined as

$$
\begin{cases}T_{p}=T_{0}+H R \cdot t & \text { for } t<\frac{T_{N}-T_{0}}{H R} \\ T_{p}=T_{N} & \text { for } t \geq \frac{T_{N}-T_{0}}{H R}\end{cases}
$$




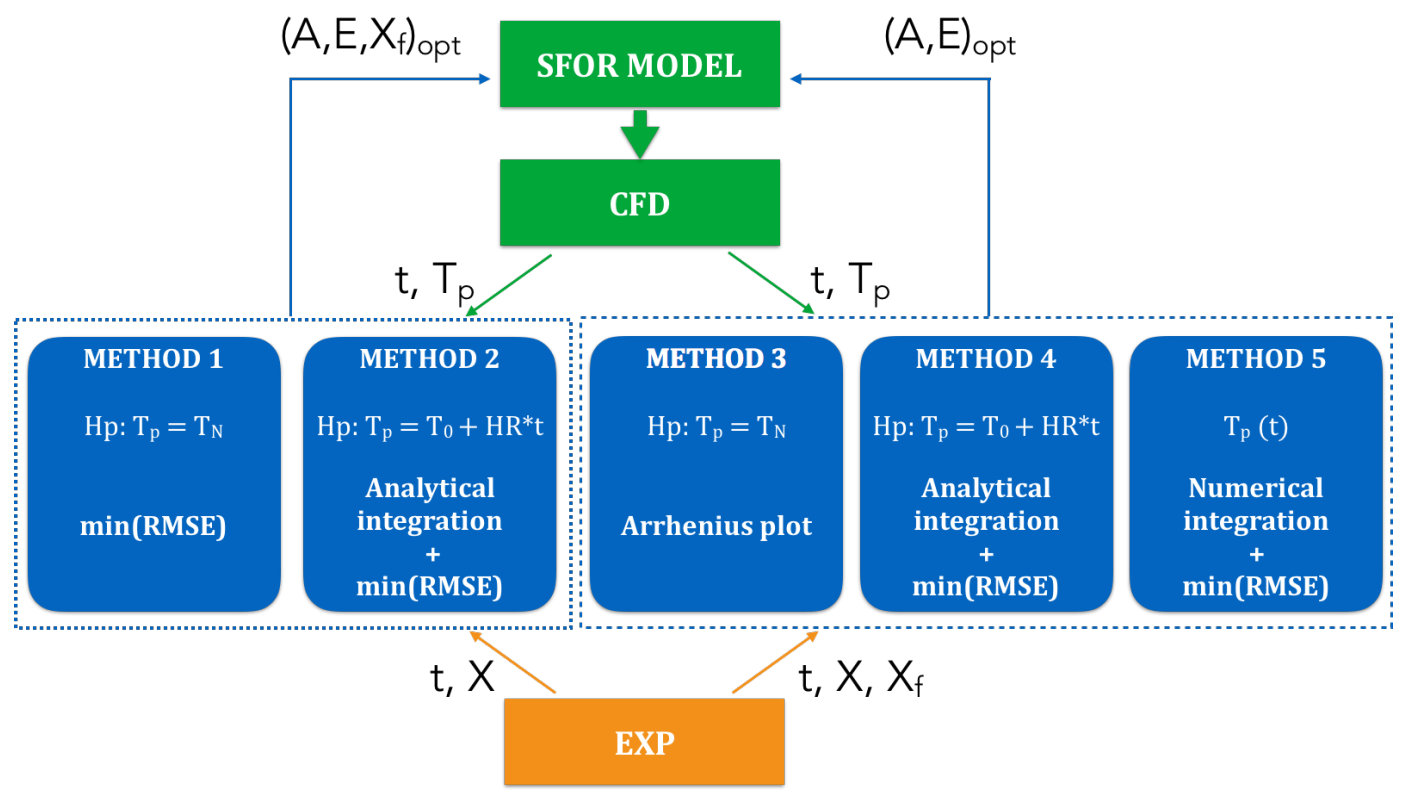

Figure 2: Methodological scheme

where $T_{0}$ is the initial temperature (assumed to be $293 \mathrm{~K}$ ), $T_{p}$ is the particle temperature, $T_{N}$ is the nominal reactor temperature and $H R$ is the heating rate of the particle in the IPFR, calculated from CFD simulations as a mean of the heating rates of the particles in the $65-90 \mu \mathrm{m}$ size range. An optimization procedure is then performed on the time/conversion correlations for all the experimental data at the three different $T_{N}$, to derive the pre-exponential factor, the activation energy and the ultimate yield. This method allows deriving kinetic parameters "sensitive" to the particle thermal history.

In the third approach, the particle temperature is taken constant and equal to the nominal IPFR temperature. The kinetic parameters are derived through an Arrhenius plot: the rates for each nominal temperature, i.e. 1173, 1373 and $1573 \mathrm{~K}$, result from a fitting procedure of the experimental conversion over residence time. The parameters $A$ and $E$ are optimized, while $X_{f}$ corresponds, for each case, to the experimental value of conversion at the highest residence time, which is high enough to allow us to claim the conversion of Sebuku coal has reached an equilibrium value. Once again, the particle residence time is derived through CFD simulations of IPFR.

The forth approach is equal to the second one, but using variable $X_{f}$ values, as in the third one.

The final approach consists in performing a numerical integration of SFOR equation over residence time, using a discretization of particle thermal history, i.e. the mean particle temperatures taken from CFD modeling at different distances from the inlet, and then applying the multivariable optimization on the pre-exponential factor and the activation energy, while $X_{f}$ corresponds to the experimental value of conversion at the highest residence time for each case. A schematic representation of the five methods and their connections with experimental and CFD data is shown in Figure 2 each of the first two methods provides three optimized parameters, namely $A, E$ and $X_{f}$, while in the last three methods $X_{f}$ is taken from the experimental results and only the kinetic parameters are optimized. 


\subsection{Simulation settings}

As mentioned before, experiments are complemented by CFD modeling, based on a two-way coupled Lagrangian tracking and developed using the fluid dynamic software Fluent, within the commercial CFD code Ansys 16. The domain consists of half IPFR because of its geometric symmetry. The chosen domain referred to the run with the larger reactor length, i.e. larger distance between feeding piper and sampling probe, to avoid creating one geometry and one mesh for each experimental run. A grid independency study on the velocity field led to 900k tetrahedral and prismatic elements. The nominal reactor temperature was set to three different values, i.e. $1173 \mathrm{~K}, 1373 \mathrm{~K}$ and $1573 \mathrm{~K}$, while the temperature of injected particles was homogeneously set to $293 \mathrm{~K}$ in all the cases. The boundary conditions are given by the experiments. The particle size distribution is Rosin-Rammler type, going from 65 to 90 $\mu \mathrm{m}$. A mass flow rate was set for the particle injection through the whole surface of the inlet probe. The dispersion of particles due to turbulence in the fluid phase was predicted using the stochastic tracking model, which includes the effect of instantaneous turbulent velocity fluctuations on the particle trajectories through the use of Discrete Random Walk (DRW) method. In addition to turbulent dispersion, drag and gravity were considered to be the forces acting on the overall 1600 particles injected. RANS equations were solved using the standard k- $\varepsilon$ turbulence models. Radiation was taken into account through the P1 radiation model and Weighted Sum of Gray Gases Model (WSGG) for the spectral properties. The particle emissivity was 0.7. A stationary solver was used to solve the equations using a second order discretization scheme and the SIMPLE algorithms for the pressure-velocity coupling. CFD modeling was performed with different levels of complexity in order to gain insight into specific flow features. Hence, different simulations were carried out corresponding to: single-phase flow, injection of inert coal particles, to estimate the particle thermal history and residence time needed for application of the approaches described in Section 3.2 , and injection of reactive particles, according to the following devolatilization laws: five one-step models, defined as SFOR Mn, where $n$ is the number of the method (in the order followed in Section 3.2), the B-T model, with parameters calculated for the Sebuku coal according to correlation in Eq. 3 , and CPD model. The implementation of B-T model in Fluent was made via bespoke User Defined Functions (UDFs).

Table 3 reports the kinetic parameters for the empirical models considered in our research.

\begin{tabular}{cccccc}
\hline Devolatilization model & ${\mathrm{A}\left[\mathrm{s}^{-1}\right]}$ & $\mathrm{E}[\mathrm{J} / \mathrm{mol}]$ & \multicolumn{3}{c}{$\mathrm{X}_{\mathrm{f}}[-]$} \\
\cline { 4 - 6 } & & & $1173 \mathrm{~K}$ & $1373 \mathrm{~K}$ & $1573 \mathrm{~K}$ \\
\hline SFOR M1 & 309.4 & $4.25 \mathrm{e} 04$ & & 0.631 & \\
SFOR M2 & 73.63 & $1.11 \mathrm{e} 04$ & & 0.478 & \\
SFOR M3 & 119.2 & $2.66 \mathrm{e} 04$ & 0.360 & 0.486 & 0.560 \\
SFOR M4 & 46.64 & $8.11 \mathrm{e} 03$ & 0.360 & 0.486 & 0.560 \\
SFOR M5 & 88.93 & $1.53 \mathrm{e} 04$ & 0.360 & 0.486 & 0.560 \\
B-T & 1068.6 & $3.39 \mathrm{e} 04$ & 0.477 & 0.531 & 0.580 \\
\hline
\end{tabular}

Table 3: Kinetic parameters values for the devolatilization models. 


\section{Results and Discussion}

The CFD simulations provide numerical predictions on coal particle tracks, residence times, thermal histories and conversions. Figure 3 shows the time spent by the particles to reach different distances from the inlet at different temperatures in the experimental and in three numerical cases. The hypothesis of isokinetic flow of particles and gases that was made during the experiments [32] is not verified, as the experimental and CFD curves have different slopes. Figure 4 shows the particle thermal histories at different nominal temperatures for the inert case. It can be observed that the particles are not heated up at same ways, because of their different diameters and tracks inside the reactor. The $68 \%$ confidence interval, corresponding to twice the standard deviation, i.e. $2 \sigma$, of the computed particle temperature is reported at each residence time. An evaluation of HRs can be carried out from these results. A linear relationship between the particle mean temperature and time was considered, leading to the assumption of a constant heating rate for each case, before the particles reach the nominal reactor temperature. This assumption was found to be good enough to approximate the particle thermal histories, especially because of the large sources of uncertainty that affect the predicted data. The simulations corroborate that a gas stream having a high $\mathrm{CO}_{2}$ concentration surrounds the particles, confirming that the particles have not enough time to mix with the surrounding gases in the main flow.

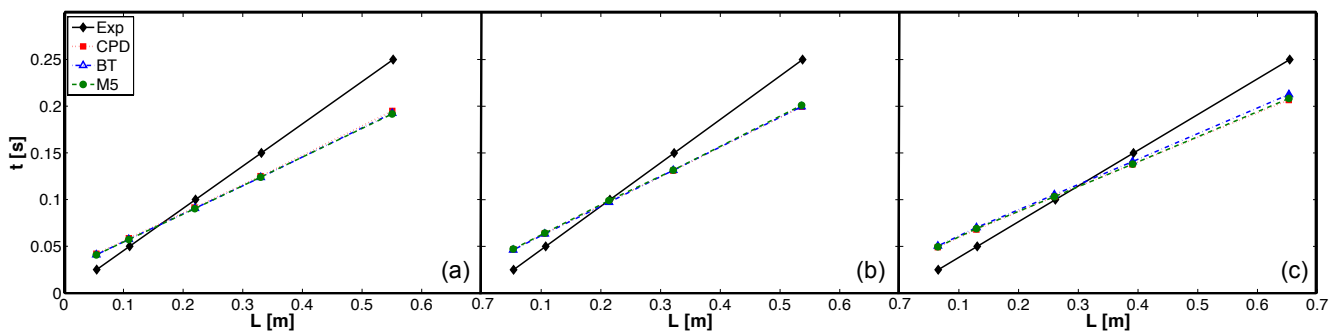

Figure 3: Time spent by the particles to reach different distances from the inlet in the experimental and in three numerical cases $(\mathrm{CPD}$, BT, M5) at $1173 \mathrm{~K}(\mathrm{a}), 1373 \mathrm{~K}(\mathrm{~b})$ and $1573 \mathrm{~K}(\mathrm{c})$.

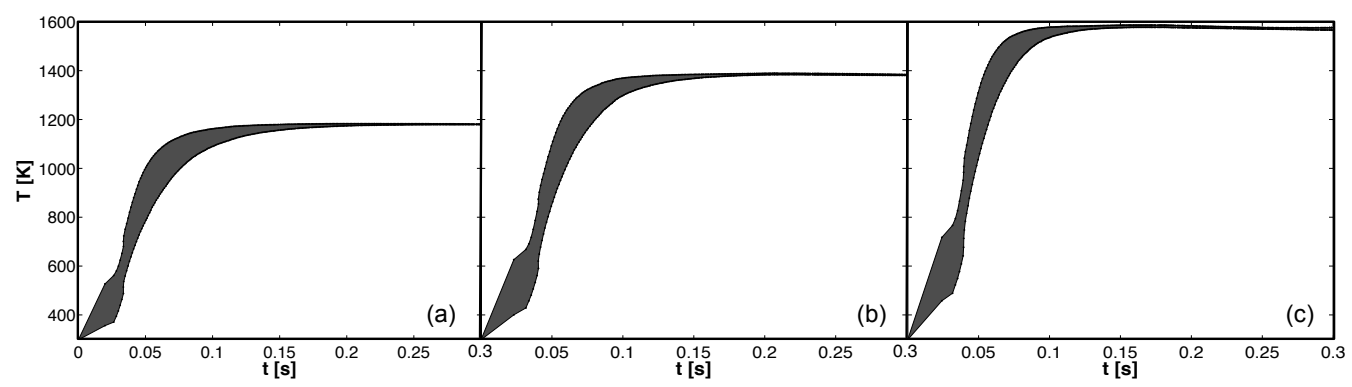

Figure 4: Particle thermal histories, with 68\% confidence interval, at $1173 \mathrm{~K}$ (a), $1373 \mathrm{~K}$ (b), $1573 \mathrm{~K}$ (c).

The coal conversion over residence time is compared for CFD models and experiments in Figures 5, 6, 7 , Error bars for experimental data are shown. Numerical results are shown in the form of mean conversion $X$ and mean residence time $t$ and corresponding standard deviations. Since the CFD results showed the experimental residence 
time was miscalculated, the data are plotted at the times derived by the CFD simulations to allow comparing the experimental and the modeled conversion.

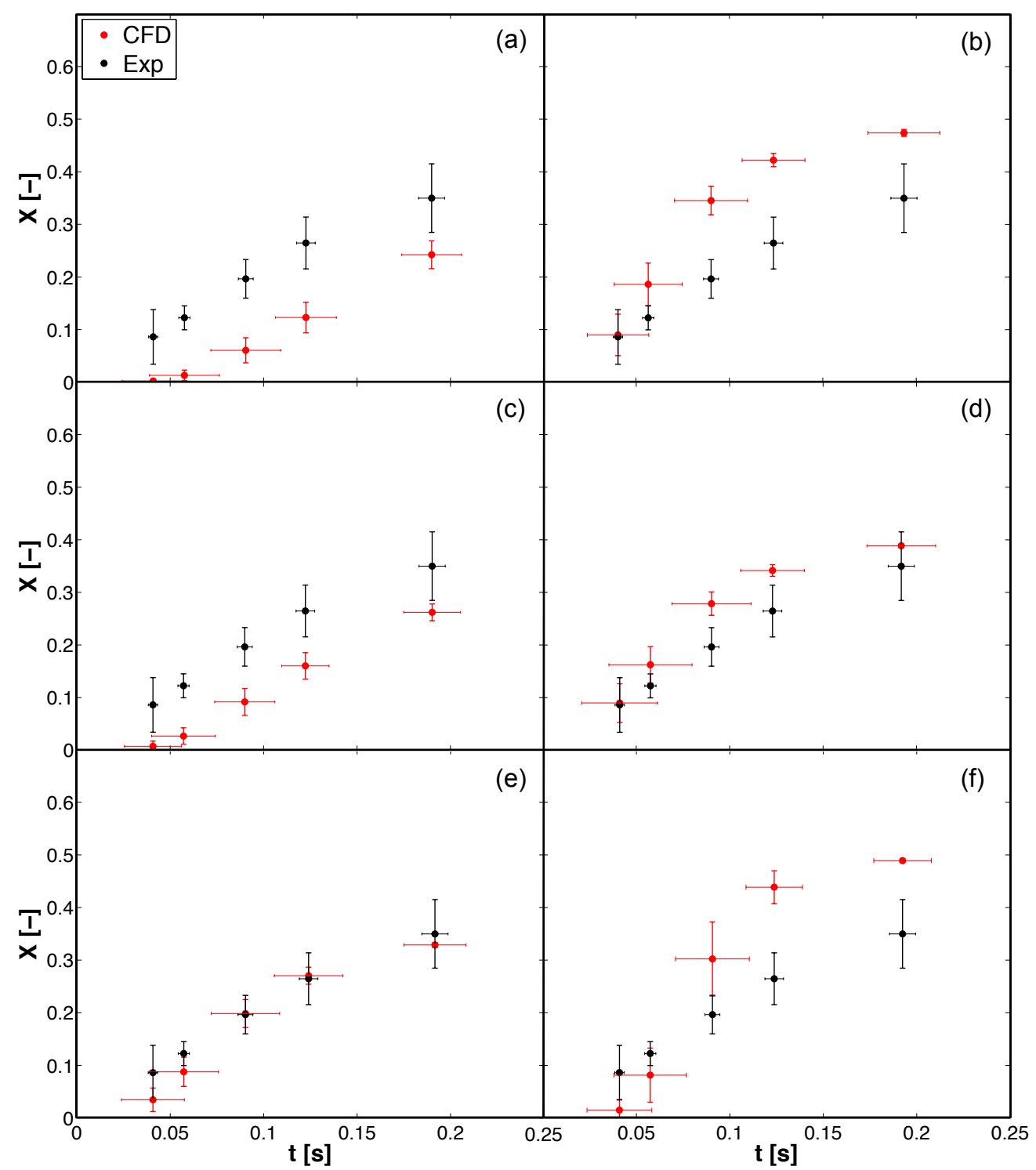

Figure 5: Conversion vs. time for SFOR M1 (a), SFOR M2 (b), SFOR M3 (c), SFOR M4 (d), SFOR M5 (e) and B-T (f) models at 1173 K.

At 1173 K, Figure 5 shows SFOR M1 and M3 models underpredict the coal conversion for the entrained reactor, as expected, since the assumption of a constant particle temperature is not correct, as pointed out by Figure 4 . This assumption leads to unbiased kinetic parameters, as for instance higher activation energies that result in low kinetics at the actual particle temperatures, thus an underestimation of particle conversion. The use of the experimental value of $X_{f}$ slightly improves the predictions. The inclusion of the particle thermal history leads to an overprediction of the yield in the SFOR M2 case, because of the high value of the optimized ultimate yield $X_{f}$, but to a good prediction in the SFOR M4 case. These results prove that considering one value of the ultimate yield, constant with temperature, although optimized, worsens the predictivity of the SFOR model (see SFOR M1 and M2 results, 
compared to SFOR M3 and M4 predictions respectively). The B-T model performances are not optimal; however, it must be stressed that model parameters are not trained on Sebuku coal. SFOR M5 model performs the best, thanks to an almost exact particle thermal history embedded in the integration of the SFOR equation.

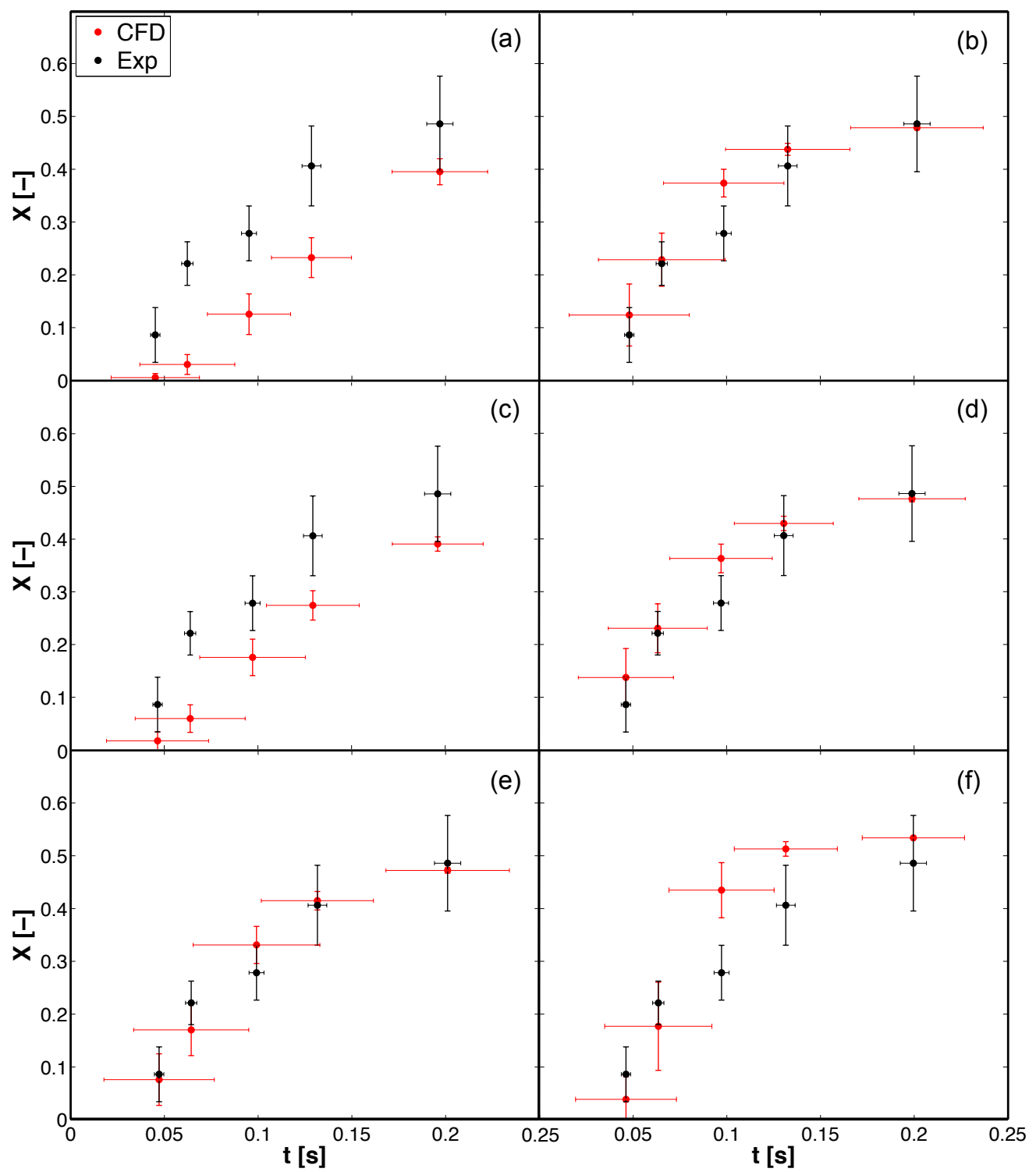

Figure 6: Conversion vs. time for SFOR M1 (a), SFOR M2 (b), SFOR M3 (c), SFOR M4 (d), SFOR M5 (e) and B-T (f) models at 1373 K.

Similar considerations can be made at higher temperature, namely 1373 K. Figure 6 shows the underprediction of SFOR M1 and M3 model, even if less severe. Both M2 and B-T show slightly better behavior at this temperature. For the latter two models, the improvement can be explained by the fact that the ultimate yield is closer to the experimental one at this temperature. SFOR M4 and M5 are able to predict the conversion trend. 


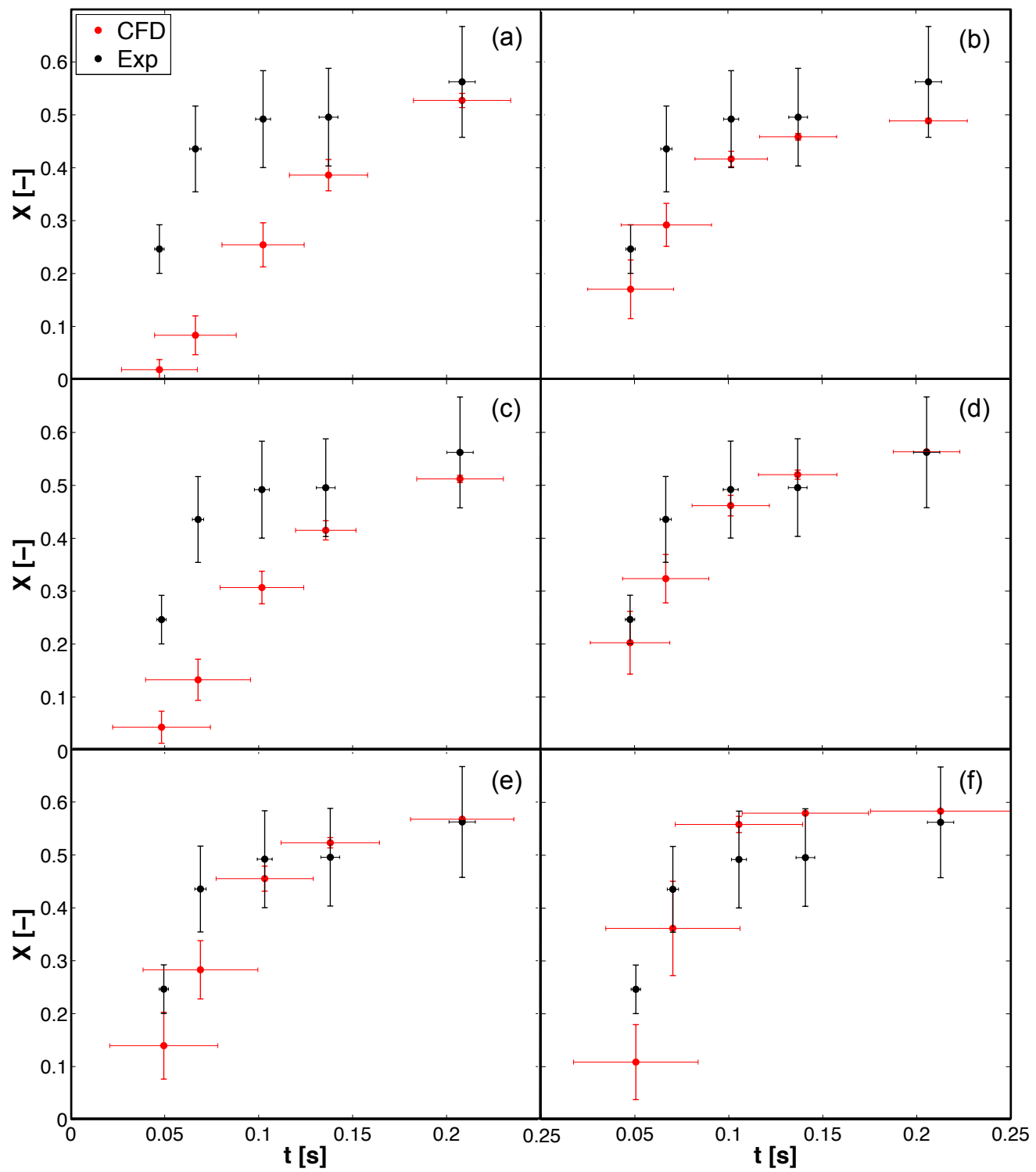

Figure 7: Conversion vs. time for SFOR M1 (a), SFOR M2 (b), SFOR M3 (c), SFOR M4 (d), SFOR M5 (e) and B-T (f) models at 1573 K.

At $1573 \mathrm{~K}$, and so for more severe conditions, Figure 7 shows how all models underpredict the yield at the initial sampling points, where the temperature gradients are higher, although better results are provided by the models taking into account the particle thermal history, i.e. SFOR M2, M4 and M5. The hypothesis of a constant heating rate, which is not realistic in general and especially for the large gradients observed at the highest temperature, does not affect the accuracy of the prediction for the SFOR M4 model. Surprisingly, the numerical integration of the SFOR equation using a discretization of the mean particle thermal history over residence times does not reduce the small discrepancy between the experimental and numerical conversion at the initial sampling points. This can be explained taking into account that other variables, besides temperature and time, should be considered in the SFOR equation, for instance an additional relation involving the ultimate volatile yield, as Biagini and Tognotti proposed. Moreover, the numerical integration procedure could be improved by weighting the mean of particle thermal histories 
considering that smaller particles have faster heating rates and therefore enhanced yields. To conclude the analysis of Figure 7, the B-T performs at its best at this temperature.

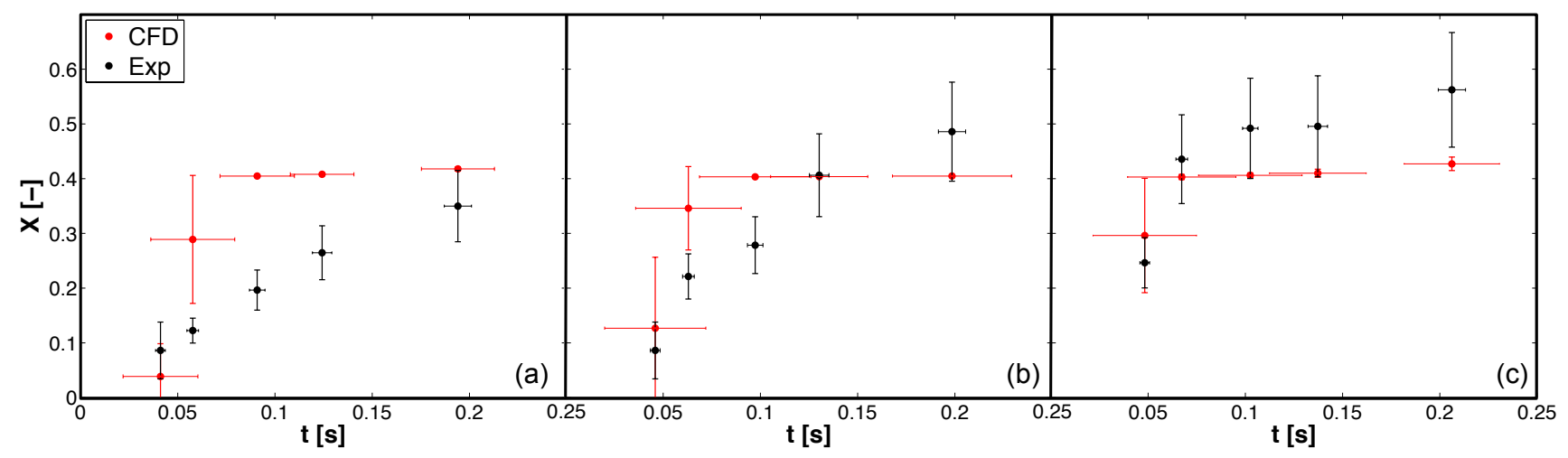

Figure 8: Conversion vs. time for CPD model at $1173 \mathrm{~K}$ (a), $1373 \mathrm{~K}$ (b), $1573 \mathrm{~K}$ (c).

As far as the CPD model is concerned, Figure 8 shows how this phenomenological model is not able to correctly reproduce the conversion trend. In particular, the ultimate yield is constant with temperature and equal to the value provided by the proximate analysis, thus leading to the observed discrepancies between predictions and experimental data. At the highest temperature, $\mathrm{CPD}$ can capture the conversion at the initial sampling points but again underestimates the yield at higher residence times.

The simulations with the CPD model were computationally more expensive; the CPU time was almost twice the one associated to the B-T model, the most demanding amongst the one-step models.

\section{Conclusions}

A numerical investigation of the IFRF's entrained flow reactor has been presented, with a particular focus on the combined experimental/numerical methodology for the development of optimal Single First Order Reaction models. Different approaches were used for the derivation of SFOR kinetic parameters, exploiting experimental and CFD data. The comparison between one-step models allowed us to shed light on their drawbacks, which can be firstly linked to the ultimate volatile yield parameter $X_{f}$ :

1. with a constant $X_{f}$ included in the one-step model equation, the same final conversion under different thermal conditions will be predicted, which is unreasonable and leads to a poor prediction of coal conversion during devolatilization;

2. a variable ultimate volatile yield, depending on particle temperature, must be taken into account in the SFOR model;

3. when the ultimate yield is supposed equal to the conversion value at the highest residence time at each temperature, the trend of the experimental data has been better predicted by the SFOR M3 and M4 models, compared to the M1 and M2 models respectively.

The poor performances of CPD model are due mainly to the constant value of the ultimate yield, although this needs to be further investigated. The non-optimal performance of the B-T model can be linked to parameters not 
perfectly tuned on the operating conditions and the coal type of interest, although the model is the first remarkable attempt to develop a comprehensive yield model, which is needed to improve the predictivity of SFOR models, when experimental data are not available. A thermodynamic model that predicts the volatile yield changes with temperature and heating rate can be therefore necessary, in addition to a simple kinetic model.

Another drawback of SFOR models is associated to the relation between particle temperature and kinetic parameters derivation: when a representative particle thermal history was considered, the devolatilization rate predicted by SFOR model was improved, and the best result was achieved by the SFOR M5, which considers the most realistic particle temperature trend. The results confirmed that coal pyrolysis is reasonably a thermal process and taking into account the heating process of coal particles is necessary to improve the predictivity of the models. Different gas mixtures surrounding the particles can have different effects on their thermal history (since for example $\mathrm{CO}_{2}$ has different thermal properties compared to $\mathrm{N}_{2}$ ), although several devolatilization experiments showed mixed results about whether the particle volatile yield is affected by the gas phase composition or not [35-38]. Considering the effects of the gas phase composition in the derivation of kinetic parameters for coal devolatilization rate is a safe assumption, especially when the ultimate research purpose is the developing of comprehensive correlations between kinetic parameters and coal specific properties.

Numerical simulations showed their capability to fill the lack of experimental uncertainty regarding flow of solid particles, consequent residence times, thermal histories and conversion in entrained flow reactors. Future work will focus on the uncertainty quantification on model parameters using different so-called instrument models, which include all the physical sub-models and the sources of uncertainty considered in the experiments and in the numerical simulations, affecting the main quantities of interest (time and temperature in this work).

Although the improvements of one-step models obtained with this calibration are valid only for the range of conditions and for the coal of interest, this benchmark work wanted to show a methodology for the calibration of simple models that can be chosen in situation where either the phenomenological models do not perform properly or their use is unwanted, particularly in the perspective of LES approach of pulverized coal combustion burners. When performing large-scale, CPU-intensive computations of coal boilers, it might be necessary to limit the complexity of physical sub-models. In this context, a reduced physical model for coal combustion can act as a scale-bridging method.

The optimization procedures described in this work are based on experimental data and CFD simulations and they can be extended to other coals and experimental test carried out in facilities that allow to reach conditions similar to those of full-scale combustion plants, namely high temperatures and heating rates. Doing so, comprehensive correlations between kinetic parameters and coal specific properties can be obtained for coal devolatilization in oxy-coal combustion industrial-like conditions.

\section{Acknowledgments}

This material is based upon work supported by the Department of Energy, National Nuclear Security Administration, under Award Number(s) DE-NA0002375. 


\section{References}

[1] E. M. Smeets, A. P. Faaij, I. M. Lewandowski, W. C. Turkenburg, A bottom-up assessment and review of global bio-energy potentials to 2050 Progress in Energy and Combustion Science 33 (1) (2007) 56 - 106. doi:http://dx.doi.org/10.1016/j.pecs.2006.08.001.

URL http://www.sciencedirect.com/science/article/pii/S0360128506000359

[2] G. Scheffknecht, L. Al-Makhadmeh, U. Schnell, J. Maier, Oxy-fuel coal combustion-A review of the current state-of-the-art, International Journal of Greenhouse Gas Control 5, Supplement 1 (2011) S16 - S35, oxyfuel Combustion Technology - Working Toward Demonstration and Commercialisation. doi:http://dx.doi.org/ $10.1016 /$ j.ijggc.2011.05.020

URL http://www.sciencedirect.com/science/article/pii/S1750583611000806

[3] L. D. Smoot, P. J. Smith, Coal combustion and gasification, Plenum Press, 1985.

[4] O. Authier, E. Thunin, P. Plion, L. Porcheron, Global kinetic modeling of coal devolatilization in a thermogravimetric balance and drop-tube furnace, Energy \& Fuels 29 (3) (2015) 1461-1468. arXiv:http: //dx.doi.org/10.1021/ef502600t, doi:10.1021/ef502600t.

URL http://dx.doi.org/10.1021/ef502600t

[5] M. Simone, E. Biagini, C. Galletti, L. Tognotti, Evaluation of global biomass devolatilization kinetics in a drop tube reactor with CFD aided experiments, Fuel 88 (10) (2009) 1818 - 1827. doi:http://dx.doi.org/10.1016/ j.fuel.2009.04.032.

URL http://www.sciencedirect.com/science/article/pii/S0016236109002087

[6] C. Zhang, X. Jiang, L. Wei, H. Wang, Research on pyrolysis characteristics and kinetics of super fine and conventional pulverized coal, Energy Conversion and Management 48 (3) (2007) 797 - 802. doi:http://dx. doi.org/10.1016/j.enconman.2006.09.003.

URL http://www.sciencedirect.com/science/article/pii/S0196890406002846

[7] J. Faúndez, A. Arenillas, F. Rubiera, X. García, A. Gordon, J. Pis, Ignition behaviour of different rank coals in an entrained flow reactor, Fuel 84 (17) (2005) 2172 - 2177, special Issue: The 5th European Conference on Coal Research and its Applications. doi:http://dx.doi.org/10.1016/j.fuel.2005.03.028.

URL http://wWw.sciencedirect.com/science/article/pii/S0016236105001298

[8] R. Jovanovic, A. Milewska, B. Swiatkowski, A. Goanta, H. Spliethoff, Sensitivity analysis of different devolatilisation models on predicting ignition point position during pulverized coal combustion in $\mathrm{O} 2 / \mathrm{N} 2$ and $\mathrm{O} 2 / \mathrm{CO} 2$ atmospheres/N2 and O2/CO2 atmospheres and O2/CO2 atmospheres, Fuel 101 (2012) 23 - 37, 8th European Conference on Coal Research and Its Applications. doi:http://dx.doi.org/10.1016/j.fuel.2011.02.024. URL http://www. sciencedirect.com/science/article/pii/S0016236111000949

[9] M. Vascellari, R. Arora, M. Pollack, C. Hasse, Simulation of entrained flow gasification with advanced coal conversion submodels. Part 1: Pyrolysis, Fuel 113 (2013) 654 - 669. doi:http://dx.doi.org/10.1016/j. 
fuel.2013.06.014.

URL http://www.sciencedirect.com/science/article/pii/S0016236113005413

[10] S. Niksa, A. R. Kerstein, FLASHCHAIN theory for rapid coal devolatilization kinetics. 1. Formulation, Energy \& Fuels 5 (5) (1991) 647-665. arXiv:http://dx.doi.org/10.1021/ef00029a006, doi:10.1021/ef00029a006 URL http://dx.doi.org/10.1021/ef00029a006

[11] T. H. Fletcher, A. R. Kerstein, R. J. Pugmire, M. S. Solum, D. M. Grant, Chemical percolation model for devolatilization. 3. Direct use of carbon-13 NMR data to predict effects of coal type, Energy \& Fuels 6 (4) (1992) 414-431. arXiv:http://dx.doi.org/10.1021/ef00034a011, doi:10.1021/ef00034a011.

URL http://dx.doi.org/10.1021/ef00034a011

[12] P. R. Solomon, D. G. Hamblen, M. A. Serio, Z.-Z. Yu, S. Charpenay, A characterization method and model for predicting coal conversion behaviour, Fuel 72 (4) (1993) 469 - 488. doi:http://dx.doi.org/10.1016/ 0016-2361(93)90106-C

URL http://www.sciencedirect.com/science/article/pii/001623619390106C

[13] D. B. Anthony, J. B. Howard, Coal devolatilization and hydrogastification, AIChE Journal 22 (4) (1976) 625-656. doi:10.1002/aic.690220403.

URL http://dx.doi.org/10.1002/aic.690220403

[14] H. Kobayashi, J. Howard, A. Sarofim, Coal devolatilization at high temperatures, Symposium (International) on Combustion 16 (1) (1977) 411 - 425. doi:http://dx.doi.org/10.1016/S0082-0784(77)80341-X. URL http://www.sciencedirect.com/science/article/pii/S008207847780341X

[15] S. Sommariva, T. Maffei, G. Migliavacca, T. Faravelli, E. Ranzi, A predictive multi-step kinetic model of coal devolatilization, Fuel 89 (2) (2010) 318 - 328. doi:http://dx.doi.org/10.1016/j.fuel.2009.07.023. URL http://www.sciencedirect.com/science/article/pii/S0016236109003548

[16] J. Yu, J. A. Lucas, T. F. Wall, Formation of the structure of chars during devolatilization of pulverized coal and its thermoproperties: A review, Progress in Energy and Combustion Science 33 (2) (2007) 135 - 170. doi:http://dx.doi.org/10.1016/j.pecs.2006.07.003

URL http://www.sciencedirect.com/science/article/pii/S0360128506000372

[17] E. Biagini, L. Tognotti, A generalized correlation for coal devolatilization kinetics at high temperature, Fuel Processing Technology 126 (2014) 513 - 520. doi:http://dx.doi.org/10.1016/j.fuproc.2014.06.008 URL http://www.sciencedirect.com/science/article/pii/S0378382014002458

[18] Solid fuel database [cited February 2016].

URL http://sfdb.ifrf.net/

[19] T. Maffei, A. Frassoldati, A. Cuoci, E. Ranzi, T. Faravelli, Predictive one step kinetic model of coal pyrolysis for CFD applications, Proceedings of the Combustion Institute 34 (2) (2013) 2401 - 2410. doi:http://dx. doi.org/10.1016/j.proci.2012.08.006

URL http://www.sciencedirect.com/science/article/pii/S154074891200377X 
[20] L. Álvarez, M. Gharebaghi, M. Pourkashanian, A. Williams, J. Riaza, C. Pevida, J. Pis, F. Rubiera, CFD modelling of oxy-coal combustion in an entrained flow reactor, Fuel Processing Technology 92 (8) (2011) 1489 - 1497. doi:http://dx.doi.org/10.1016/j.fuproc.2011.03.010.

URL http://www.sciencedirect.com/science/article/pii/S0378382011001020

[21] A. H. Al-Abbas, J. Naser, D. Dodds, CFD modelling of air-fired and oxy-fuel combustion of lignite in a $100 \mathrm{KW}$ furnace, Fuel 90 (5) (2011) 1778 - 1795. doi:http://dx.doi.org/10.1016/j.fuel.2011.01.014. URL http://www.sciencedirect.com/science/article/pii/S0016236111000160

[22] Q. Fang, A. A. B. Musa, Y. Wei, Z. Luo, H. Zhou, Numerical simulation of multifuel combustion in a 200 MW tangentially fired utility boiler, Energy \& Fuels 26 (1) (2012) 313-323. arXiv:http://dx.doi.org/10.1021/ ef 201149p, doi:10.1021/ef201149p.

URL http://dx.doi.org/10.1021/ef201149p

[23] B. W. Brown, L. D. Smoot, P. J. Smith, P. O. Hedman, Measurement and prediction of entrained-flow gasification processes, AIChE Journal 34 (3) (1988) 435-446. doi:10.1002/aic.690340311.

URL http://dx.doi.org/10.1002/aic.690340311

[24] H. Watanabe, M. Otaka, Numerical simulation of coal gasification in entrained flow coal gasifier, Fuel 85 (12-13) (2006) 1935 - 1943. doi:http://dx.doi.org/10.1016/j.fuel.2006.02.002.

URL http://www.sciencedirect.com/science/article/pii/S0016236106000548

[25] A. Slezak, J. M. Kuhlman, L. J. Shadle, J. Spenik, S. Shi, CFD simulation of entrained-flow coal gasification: Coal particle density/sizefraction effects, Powder Technology 203 (1) (2010) 98 - 108. doi:http://dx.doi. org $/ 10.1016 / j \cdot$ powtec. 2010.03 .029 .

URL http://wWw.sciencedirect.com/science/article/pii/S0032591010001579

[26] J. Ma, S. E. Zitney, Computational Fluid Dynamic modeling of entrained-flow gasifiers with improved physical and chemical submodels, Energy \& Fuels 26 (12) (2012) 7195-7219. arXiv:http://dx.doi.org/10.1021/ ef301346z, doi:10.1021/ef301346z.

URL http://dx.doi.org/10.1021/ef301346z

[27] A. Williams, R. Backreedy, R. Habib, J. Jones, M. Pourkashanian, Modelling coal combustion: the current position, Fuel 81 (5) (2002) 605 - 618. doi:http://dx.doi.org/10.1016/S0016-2361(01)00158-2.

URL http://www.sciencedirect.com/science/article/pii/S0016236101001582

[28] P. Edge, M. Gharebaghi, R. Irons, R. Porter, R. Porter, M. Pourkashanian, D. Smith, P. Stephenson, A. Williams, Combustion modelling opportunities and challenges for oxy-coal carbon capture technology, Chemical Engineering Research and Design 89 (9) (2011) 1470 - 1493, special Issue on Carbon Capture \& Storage. doi:http://dx.doi.org/10.1016/j.cherd.2010.11.010

URL http://www.sciencedirect.com/science/article/pii/S0263876210003515

[29] O. T. Stein, G. Olenik, A. Kronenburg, F. Cavallo Marincola, B. M. Franchetti, A. M. Kempf, M. Ghiani, M. Vascellari, C. Hasse, Towards comprehensive coal combustion modelling for LES, Flow, Turbulence and 
Combustion 90 (4) (2012) 859-884. doi:10.1007/s10494-012-9423-y.

URL http://dx.doi.org/10.1007/s10494-012-9423-y

[30] E. Biagini, L. Biasci, M. Marcucci, Description of the isothermal plug flow reactor and the experimental procedures for combustion studies on solid fuels, Tech. Rep. G03/y/03, IFRF (2010).

[31] E. Biagini, G. Bonvicini, G. Coraggio, M. Faleni, Development of the experimental procedures for advanced biofuels characterization in the isothermal plug flow reactor, Tech. Rep. G27/y/01, IFRF (2013).

[32] G. Bonvicini, G. Coraggio, M. Faleni, Coal characterization in oxy-firing conditions using the isothermal plug flow reactor. part 1 - methodology, Tech. Rep. G 26/y/01, IFRF (2013).

[33] E. Biagini, F. Barontini, G. Bonvicini, G. Coraggio, L. Tognotti, Advanced characterization of biofuels for combustion and gasification plants, Chemical Engineering Transactions 37 (2014) 493-498. doi:10.3303/CET1437083.

URL http://www.scopus.com/inward/record.url?eid=2-s2.0-84899413621\&partnerID=40\&md5= d2f9af3defa92894654369601ccf83e5

[34] G. J. Goetz, N. Y. Nsakala, R. L. Patel, T. C. Lao, Combustion and gasification kinetics of chars from four commercially significant coals of varying rank, in: Second Annual Contractors' Conference on Coal Gasification, 1982.

[35] A. G. Borrego, D. Alvarez, Comparison of chars obtained under oxy-fuel and conventional pulverized coal combustion atmospheres, Energy \& Fuels 21 (6) (2007) 3171-3179. arXiv:http://dx.doi.org/10.1021/ ef700353n, doi:10.1021/ef700353n

URL http://dx.doi.org/10.1021/ef700353n

[36] R. K. Rathnam, L. K. Elliott, T. F. Wall, Y. Liu, B. Moghtaderi, Differences in reactivity of pulverised coal in air (o2/n2) and oxy-fuel (o2/co2) conditions, Fuel Processing Technology 90 (6) (2009) 797 - 802. doi:http: //dx.doi.org/10.1016/j.fuproc.2009.02.009.

URL http://www.sciencedirect.com/science/article/pii/S0378382009000411

[37] X. Li, R. K. Rathnam, J. Yu, Q. Wang, T. Wall, C. Meesri, Pyrolysis and combustion characteristics of an indonesian low-rank coal under o2/n2 and o2/co2 conditions, Energy \& Fuels 24 (1) (2010) 160-164. arXiv: http://dx.doi.org/10.1021/ef900533d, doi:10.1021/ef900533d

URL http://dx.doi.org/10.1021/ef900533d

[38] J. Brix, P. A. Jensen, A. D. Jensen, Coal devolatilization and char conversion under suspension fired conditions in o2/n2 and o2/co2 atmospheres, Fuel 89 (11) (2010) 3373 - 3380. doi:http://dx.doi.org/10.1016/j.fuel. 2010.03 .019 .

URL http://www.sciencedirect.com/science/article/pii/S0016236110001110 